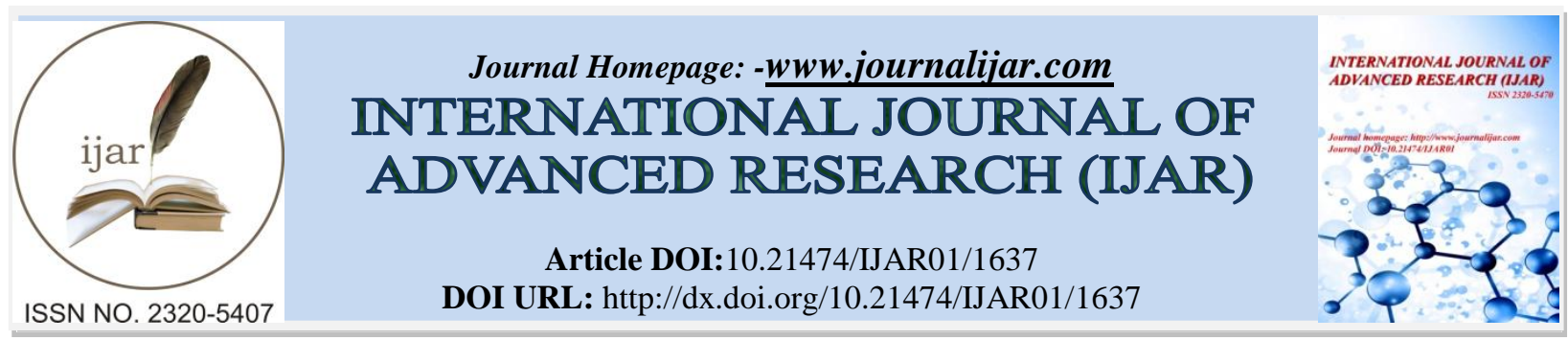

RESEARCH ARTICLE

\title{
EFFECTS OF REINFOCRCEMENT STRATEGIES ON SENIOR SECONDARY SCHOOLS STUDENTS ACHIEVEMENTS IN MATHEMATICS.
}

\author{
Osakwe Jude Odiakaosa ${ }^{1}$ and Ekoja Andrew ${ }^{2}$ \\ College of Education, Oju, Benue State, Nigeria ${ }^{1}$, University of Agriculture, Makurdi, Nigeria ${ }^{2}$
}

\section{Manuscript Info}

Manuscript History

Received: 12 July 2016

Final Accepted: 13 August 2016

Published: September 2016

Key words:-

Reinforcement, Mathematics,

Achievement, Education.

\section{Abstract}

This research was designed to study the effect of three reinforcement strategies praises, token and stories of successful and great mathematicians on mathematics achievement of secondary school students. Five hypotheses were formulated. Achievement was measured by constructing and administering mathematics objective test which was found to have significant internal consistency after subjecting the data to analysis using SPSS (Statistical Package for Social Sciences). It yielded a Cronbach alpha of 0.83. The control and experimental groups were made up of a combination of 20 boys and 20 girls for the control group and 20 boys and 20 girls for the experimental group. These were randomly sampled from SSII student of Government Secondary School, Oju, made up of a total population of 150 students. The experimental group experienced treatment with the reinforcement strategies for four weeks after which both the control group and experimental group were subjected to another achievement test in which some finding emerged. It was recommended that teachers should make use of praises, tokens and success stories as means of enhancing mathematics achievement among secondary school students.

Copy Right, IJAR, 2016,. All rights reserved.

\section{Introduction:-}

Mathematics is as old as man for the fact that counting is as old as man. People are involved in counting and all other forms of mathematical calculations. In schools, students are also involved in mathematics education starting from nursery level to the tertiary level. Mathematics instructions given at these levels are usually useful not only in the school but also in the outside world.

It is often said that mathematics is the key to science. Like a key, mathematics is therefore needed so as to enable us penetrate into science. As put by Gnedenko and Khalil (1999) mathematics like a surgeon's scalpel has allowed us to penetrate into the characteristics of phenomena. Kynch (1980) sees the subject as a must for students. This is further emphasized by Ejike (2002) who asserted that sound and thorough understanding/knowledge of mathematics predetermines future success in various disciplines.

Despite the high position mathematics assumes in the overall education, most especially in the area of sciences and all other field of education, coupled with the different strategies employed in its instruction, student achievement in the subject is still very low.This usually happens because most of these students according to Cotton (2005) are permanently 
on the belief that mathematics is an unconquerable phenomenon. He further stressed that mathematics anxiety in students if not properly handled, could lead to a situation where most of them will fail to respond to reinforcement. Earlier, Okorie (2002) stated that students with high level of mathematics anxiety achieve lower in mathematics than students with low level of mathematics anxiety. Also Okebukola (1996)noted that the determinant of mathematics achievement is teacher's behavior. He asserted that the way teachers devote time to teach mathematics and the way they present the subject to the students go a long way in determining their level of achievement.

\section{Reinforcement Defined:-}

According to Cotton (2005) the modern history of reinforcement began with the proliferation of theories and experimental work in the area of behavior modification in the 1950s and 1960s. A great many studies were undertaken and many theories were advance regarding the use of reinforcement to manage human and animal behaviour. In the words of Freidman (2009), reinforcement refers to the event that follows the target behaviour. This could come in form of inducement or rewards on the behaviour of a particular student. This means that it is any consequence that increases the frequency of behavior.The most important and most powerful reinforce in the classroom is the teacher attention (Conroy, Sutherland,Snyder,Al-Hendawi,\&Vo,2009). Others are praises, token, grades and promotion. This kind of reinforcement given to students serves as a kind of encouragement and a morale booster which motivate them into trying achieve more.

Also, Cotton (2005) sees reinforcement as the provision of verbal, symbolic, tangible or other rewards for desirable academic performance or effort at the classroom level. He also went ahead to outline them as.

1. Praise (and other verbal reinforcement) for correct responses during class discussion, accurate homework improved test scores etc

2. Token Reward- Such as point or chips, which are valueless in themselves, but which can be redeemed for things of value.

3. Symbolic Reward: Such as having one's picture on bulletin board or name in a newsletter.

4. Tangible Reward: Such as edible, toys or school related items (pencil, notebooks etc).

5. Activity Reward: Such as free time, being a leader of an activity, going on field trip etc. in Continuing Cotton noted that the most common type of reinforcement is the praise type. He asserted that this type of reinforcement is commonly used by teachers. He assumed that praise has reinforcing effects on student's academic achievement.

It is an overall view that praise can enhance learning if it is cogent, specific, sincere and credible.

\section{Formation of Reinforcement:-}

Many factors determine the formation of reinforcement. One of them is the state of an individual, Singh. (1991). What influences the state of an individual to change determine, to a great extent, his behavior to some situations around him.Cannella (1986) asserted that related physiological changes as in hunger or thirst can quickly alter attitudes towards food or water.Belliot (2003) also feels that attitudes may be affected through experience. Thus when people belong to one group of interaction between them brings about cross fertilization of ideas and so enhance the formation of reinforcement.

All Port (2002) gave three levels in which reinforcement are formed. They include integrated, differentiation and trauma. Integrated stage is that which numerous specific responses are organized and structured in an individual during this period, an individual does not react to any of these responses. For instance, in different subject as various responses and at the stage of integration, he may not show any reaction to any of the intense emotional experience he had with various responses. This means he has taken a firm stand on the subject he likes and forms a positive attitude on the subject or he may dislike any of them and form negative reinforcement on these subjects.

\section{Reinforcement Component:-}

Reinforcement, after it is formed, exist in three identifiable components, the components of reinforcement according to Traverse are cognitive mental) effective and psychomotor.The cognitive component of reinforcement involves knowledge and beliefs. Traverse in Okorie (2003) asserts that some reinforcements are highly intellectualized. Some may occupy a particular position in a certain issue because all the available evidence have to strike his decision and feels his decision is then most acceptable one.

Hallahan, Kauffman and Lioyd (1996) posited that the goal of cognitive behavior modification is to change not only the person's awareness of the behavior and thinking associated with it.Sometimes reinforcement could be based on a large 
store of information and false beliefs, for instance in one's attitude towards a subject, the cognitive aspect embraces the stereo-typed beliefs (valid or misinformed). He may hold the group ability and so on.

\section{Reinforcement and Mathematics Achievement:-}

In a study conducted by Scholfield (1981), reinforcement strategies were directly linked to student performance in and students' attitude towards mathematics. Results indicated that good reinforcement produce high-achieving students.Cruik and Sheffield (1992) wrote that they unconvinced that students suffer from mathematics anxiety. Instead, they argued that teachers, who fail to implement seven important measures, cause their students to have low achievement in mathematics.

These measures include teachers who;

a. Show that they like mathematics

b. make mathematics enjoyable

c. Show the use of mathematics in careers and everyday life

d. Adopt instruction to students interest

e. Establish short-term attainable goals

f. Provide successful activities

g. Use meaningful methods of teaching so that mathematics makes sense.

In addition to these measures, Reys, Suydam and Lindquist (1995) suggested de-emphasizing speed tests or drills and avoiding competition among students in order to reduce chances of fear of mathematics. They also added that communicating about mathematics events that occur in the classroom would enhance mathematics power.

From an academic standpoint, Post (1992) warned that negative attitude towards mathematics can produce negative results due to the reduction in reinforcement strategies.Dutton and Dutton (1991) posited that the willingness to pursue advanced work in mathematics, even the choice of prospective occupation influences students' achievement in mathematics.Rey, Suydam and Lindquist (1995) again stated that the gorge that exist between great achievement in mathematics and poor performance is due to low motivation (reinforcement).

The number of research studies in mathematics education over the past three decades has increased dramatically (Kilpatrick 1992). Research findings indicate that certain teaching strategies and methods are worth careful consideration as teachers strive to improve their mathematics teaching practices. It was observed that focusing instruction on the meaningful development of important mathematical ideas increase the level of student learning

There is a long history of research going back to the work of Brownell $(1945,1947)$, on the effects of teaching for meaning and understanding. Investigation have consistently shown that an emphasis on teaching for meaning has positive effects on students learning including better initial learning, greater retention and increased likelihood that the idea will be used in new situation. Brownell also suggests that students who develop conceptual understanding early perform best on procedural knowledge later. Student with good conceptual understanding are able to develop procedural knowledge later. Student with good conceptual understanding are able to develop procedures and skills they have been taught.

Davidson (1998) reviewed studies that compared student achievement in small group setting with traditional whole class instruction. In more that $40 \%$ of these studies, students in the class using small group approaches significantly outscored control studies on measures of students performance.

Long-term use of concrete materials is positively related to increases in student mathematics achievement and improved attitudes towards mathematics. In a review of activity based learning in mathematics in Kindergarten, Suydam and Higgins (1997) concluded that using manipulated materials produce greater achievement than not using them.In as much as concrete materials increase student achievement in mathematics, new studies strongly indicate that teacher attitudes and actions influence students' sense of their ability in mathematics and science. Teachers need to give more sense of motivation to students by improving instructional practices that promote interest and success.

Teachers have great part to play in the effectiveness of subject. When teachers fail to realize this fact therefore leads to inefficiency in teaching. However there is lukewarm attitude of school teachers and their low motivational skills 
in school which consequently leads to the downward slide of mathematics achievement of students (Simon, Tzur, Heinz, Smith\&Kinzel, (1999).

\section{Attitude Towards Mathematics and Mathematics Performance:-}

The individual manifest his attitude whenever the situation calls for.There has been an interest in the development of positive student attitude towards mathematics. The objective of any mathematics curriculum include fostering favourable feeling towards mathematics as well as imparting cognitive knowledge (Bolaji 1996)

It is a long established belief that psychological elements in the teacher play a central role in the teaching and learning of mathematics. In particular, many researchers have held the view that there is an important relationship between the attitude of teachers towards the teaching of mathematics, there is also the teacher's attitude to the teaching of mathematics. Therefore there is every reason to believe that attitudes to teaching mathematics is just as important as a factor in contributing to the development of student attitude and achievement in mathematics.

\section{The problem of the study:-}

1. Lack of motivation and reinforcement on the part of the teacher leads to students' poor performance/achievement in mathematics

2. Students' negative attitude towards teaching and learning mathematics is due to teachers' negative reinforcement.

3. Teacher's poor method of teaching is also a great problem on mathematics students' achievement.

\section{Research Questions:-}

The following questions were formulated for the study:

1. Is there any significance sex difference in pre-test achievement scores for control group?

2. Is there any significant sex difference in pre test achievement scores for treatment group?

3. Is there any significant difference in pre test control and treatment groups in the achievement score?

4. Is there any significant difference in post test achievement scores between treatment and control group?

5. Is there any significant mean effect of treatment factor on achievement scores of studied subject?

\section{Research Hypothesis:-}

The following hypothesis were formulated for the study at the 0.05 level of confidence:

i. There is no significant sex difference in pre-test achievement score for control group.

ii. There is no significant sex difference in pre-test achievement score for treatment group.

iii. There is significant difference between pre-test control and treatment groups in the achievement scores.

iv. There is no significant difference in post test achievement scores between treatment and control group

v. There is no significant main effect of treatment factor on achievement scores of experimental group.

\section{Materials and Methods:-}

\section{Population:-}

The population was obtained from four arms of SSII students of a Government Secondary School. The total number of students in this class (SSII) is one hundred and fifty (150).

\section{Sample/sampling Techniques:-}

Out of the one hundred and fifty (150) student in SSII, eighty (80) were randomly selected. This eighty (80) is made up of forty girls and forty boys. The randomization was done after listing the total number of SSII student in the school and then obtaining the required 40 (forty) from the group of boys and girls. This was done by using the simple random sampling technique so as to give the students the equal chance of being selected.

\section{Instrument:-}

In order to actualize the study, the researcher employed the use of two tests. The treatment factor for the experimental group and two mathematics achievement tests for the pre-test and post-test. Fifty (50) questions were given with options. Students were instructed to choose the correct answer from the options given in each question.

Each question answered correctly attracts two (2) marks while an incorrect answer is equal to zero (0). Also, the total score is equal to 100 (i.e $2 \times 50=100$ ). 


\section{Administration:-}

The students were divided into a group of 40 made up of twenty (20) boys and twenty (20) girls. One of the group (group A) served as the control group, while the other group (group B) served as the treatment group. A pre-test was administered under normal examination situation.

The two groups were examined in different halls of the same size and at the same time. The Pre-test unfolded the actual performance of the students. Thereafter, lessons were organized for the two groups. In group A (control group), mathematics was taught without any form of treatment, while in group B, various treatments were applied. These treatments were in the form of praises, the use of praises, tokens and telling of success stories of mathematicians.

At the end of the lessons, a post-test was carried out under classroom situation, and as usual, the two groups were examined in different halls of the same size and space. They all started at the same time and were given $1 \mathrm{hr} 40$ minutes (one hour forty minutes) to answer the questions, which means that they had 2 minutes per question. Also an assistant was on hand to handle the supervision of one of the classes. This assistant was given specific instructions on how to perform his responsibilities in the class.

\section{Reliability Of Instrument:-}

To arrive at the Cronbach alpha for the instrument used for this study, the data was subjected to analysis using SPSS (Statistical Package for Social Sciences) Version 10. The reliability coefficient was found to be 0.83 . This shows that the instrument used for the study was internally consistent. The split half reliability for equal length was 0.70 and 0.78 respectively.

\section{Technique of Data Collection:-}

After the test (at the expiration of the time given for the test), the answer sheets were collected starting from the first student to the last.

\section{Techniques of Data Analysis:-}

The statistical tool used for this analysis is the Analysis of Variance (ANOVA) and t-test. This enabled the researcher to test the hypothesis of the study. The data was subjected to SPSS (Statistical Package For Social Sciences).

\section{Results of the Study:-}

The first hypothesis states that there is no sex difference in pre-test achievement scores in mathematics for control group. The table that provides results in respect of the above hypothesis is shown in the table below

Table 1:- t-Test Showing Sex Differences in Pr-Test Achievement Scores in Mathematics Control Group

\begin{tabular}{|l|l|l|l|l|l|l|l|l|}
\hline Group & N & Mean & Std. Deviation & Std Error Mean & Df & T calculated & T table & P \\
\hline $\begin{array}{l}\text { Pre-test maths achievem } \\
\text { score for control grd } \\
\text { (females) }\end{array}$ & 21.4000 & 8.1072 & 1.8128 & 38 & 0.040 & 1.6839 & $\begin{array}{l}>0.05(\text { not } \\
\text { sig). }\end{array}$ \\
\hline $\begin{array}{l}\text { Pre- test achievement sc } \\
\text { for control group (males) }\end{array}$ & 20 & 21.5000 & 7.5079 & 1.6788 & & & & \\
\hline
\end{tabular}

The table above shows that there is no significant sex difference in pre-test achievement score for control group ( $t$ calculated $=-0.040 ; \mathrm{t}$ - table $-1.6839 ; \mathrm{p}>0.05$; not significant).

This means that the alternative hypothesis is rejected, while the null hypothesis is accepted.

The second hypothesis states that there is significant sex difference in pre-test achievement scores in mathematics for treatment group. The table that provides results in respect of the above hypothesis is shown in the table below.

Table 2 :- t-Test showing Sex Difference In Pre-Test Achievement Score In Mathematics for Treatment Group

\begin{tabular}{|l|l|l|l|l|l|l|l|l|}
\hline Group & N & Mean & Std. Deviation & Std Error Mean & Df & T calculated & T table & P \\
\hline $\begin{array}{l}\text { Pre-test maths achievem } \\
\text { score for control grd } \\
\text { (females) }\end{array}$ & 18.1000 & 5.8571 & 1.3097 & 38 & 110 & 1.6839 & $\begin{array}{l}>0.05(\text { not } \\
\text { sig). }\end{array}$ \\
\hline $\begin{array}{l}\text { Pre- test achievement sc } \\
\text { for control group (males) }\end{array}$ & 20 & 17.9000 & 5.6373 & 1.2605 & & & & \\
\hline
\end{tabular}


The table shows that there is no significant sex difference in pre-test achievement scores for treatment group (tcalculated $=.110 ;$ table $=1.685 \mathrm{p}>0.05$; not significant)

The third hypothesis for this study states that there is no significant difference between control and treatment groups in maths achievement scores.

The result from the data for the above hypothesis is shown in table 4.3 below.

Table 3:- t-Test showing Difference In Pre-Test Achievement Scores In Mathematics For Control And Treatment Groups.

\begin{tabular}{|l|l|l|l|l|l|l|l|l|}
\hline Group & $\mathrm{N}$ & Mean & Std. Deviation & Std Error Mean & Df & T calculated & T table & P \\
\hline $\begin{array}{l}\text { Pre-test maths } \\
\text { achievement score for } \\
\text { control group (females) }\end{array}$ & 40 & 8.000 & 5.6750 & .8973 & & & & \\
\hline $\begin{array}{l}\text { Pre- test achievement score } \\
\text { control group (males) }\end{array}$ & 40 & 1.4500 & 7.7126 & .2195 & 78 & -2.279 & 1.6641 & $>0.05(\mathrm{sig})$. \\
\hline
\end{tabular}

The above table shows that there is a significant difference between the pretest achievement scores in maths for control and treatment groups.

This implies that the null hypothesis is rejected and its alternative accepted.

Hypothesis 4 states that there is no significant difference between post test achievement scores in mathematics between treatment and control groups the results of the data from the above hypothesis is shown below.

Table 4:- T-Test Difference Between Post Test Scores Of Control And Treatment Groups

\begin{tabular}{|l|l|l|l|l|l|l|l|l|}
\hline Group & $\mathrm{N}$ & Mean & Std. Deviation & Std Error Mean & Df & T calculated & T table & P \\
\hline Pre-test treatment group & 40 & 31.9000 & 6.7778 & 1.0717 & & & & \\
\hline Pre-test control group & 40 & 21.4000 & 7.2352 & .1440 & & & & \\
& & & & & 78 & 6.698 & 1.6641 & $>0.05(\mathrm{sig})$ \\
\hline
\end{tabular}

The above table 4 is indicative of the fact that there is a significant difference between post test achievement scores in mathematics for control and treatment groups in favour of the treatment group. (treatment group mean $=31.9000$ while the control group mean $=21.4000$ )

This means that the reinforcement strategies employed on the experimental group enhanced their better performance in mathematics over that of the control group. Hence the null hypothesis is rejected while its alternative is retained.

The fifth states that there is no significant main effect of treatment factor (positive reinforcement) on achievement scores in mathematics of the experimental group.

The result of data analysis for the above hypothesis is shown in the table below.

Table 5:-Analysis of Variance (ANOVA) Showing the Effect of Treatment Factor on Achievement Scores in Mathematics of Experimental Group.

\begin{tabular}{|l|l|l|l|l|l|}
\hline & $\begin{array}{l}\text { Sum of } \\
\text { squares }\end{array}$ & Df & Mean squares & F & P \\
\hline $\begin{array}{l}\text { Between } \\
\text { (combined) }\end{array}$ & 2205.000 & 1 & 2205.000 & 44.869 & \\
\hline Within groups & 3833.200 & 78 & 49.144 & & \multirow{2}{*}{$<.05$ (significant) } \\
\hline Total & 6038.200 & 79 & & & \\
\hline
\end{tabular}

The table 5 shows that there is a significant effect of the treatment factor (reinforcement) in enhancing the achievement score in mathematics for the experimental group. This means that the null hypothesis is rejected and its alternative is retained. 


\section{Discussion:-}

Hypothesis 1 and 2 showed that sex differences are not criteria for mathematics achievement. Both the treatment and control groups' scores are evidences to that fact. This, according to Okorie (2002), means that students' intellectual capability also plays a great part in their positive development in mathematics.

Also hypothesis 4 and 5 were indicative of the fact that there is significant difference in the treatment and control group. With their group means standing at 31.9000 and 21.400 respectively (in favour of the treatment group), it means that positive reinforcement strategies go a long way to improving and enhancing student mathematics achievement

The analysis brought to fore the importance of reinforcement. This vindicated Scholfield (1999) when he said that reinforcement strategies were directly linked to student performance in and students' attitude towards mathematics. In other words reinforcement strategies enhance mathematics achievement as seen in the post test scores of the treatment group.

Furthermore, Scholfield, Cruik and Sheffield (1992) posited that teacher who fails to implement some important reinforcement measures cause their students to have low achievement in mathematics.

\section{Recommendations:-}

In the words of Kilpatrick (1992), certain teaching strategies and methods are worth careful consideration as teachers strive to improve their mathematics teaching practices. These include the followings;-

1. Teachers should focus instruction on the meaningful development of important mathematics ideas to increase the level of student learning.

2. Long term use of concrete materials is positively related to increases in students' mathematics achievement Therefore this should be encouraged from the kindergarten level.

\section{Conclusion:-}

From the finding of these studies, the following conclusions are made viz:

1. Sex differences do not effect mathematics achievement

2. Positive reinforcement strategies enhance mathematics achievement in support of previous findings in this field (Scholfield 1999).

This means that positive treatment factors are important and help greatly in mathematics achievement.

\section{References:-}

1. Allport, A., \& Wylie, G. (2000). Task switching, stimulus-response bindings and negative priming. In S. Monsell\& J. Driver (Eds.), Control ofcognitive processes: Attention and performance XIII (pp. 3570).Cambridge, MA: MIT Press.

2. Belliot G.S. (2003) Effects of Individual learning Expectation on students schools, John Hopkins University.

3. Bolaji C. (1996) Gender Difference And The Use of Two Approaches In The Teaching of Algebra. Timbari. Kano Journal of Education, vol 3, 24-25.

4. Brownell W.A. (1947) The Place Of Meaning In The Teaching Of Arithmetic "Elementary school Journal 47, 256 65.

5. Canella G.S. (1986) Praise and concrete Rewards: Concerns for childhood Education "CHILDHOOD EDUCATION RESEARCH 50 273-291.

6. Conroy, M. A., Sutherland, K. S., Snyder, A., Al-Hendawi, M., \&Vo, A.(2009). Creating a positive classroom atmosphere: Teachers' use ofeffective praise and feedback. Beyond Behavior, 18-26. Retrieved March11, 2010, from ERIC database.

7. Cotton K. (2005) Instructional Reinforcement School Improvement Research series (http://www.nwrel.org/idex.htmlhttp://www.nwrel.org/index.

8. Cruik D.E. and Sheffield J. (1992) Teaching And Learning Elementary And Middle School Mathematics. New York: Merrill 24

9. Davidson N. (1998) Small Group Cooperative Learning In Mathematics.

10. A selective view of the research. In R Slavin (Ed) "Learning to cooperate, cooperating to learn. " (Pp.211-30) NY: Plenum s 
11. Dutton W.H and Dutton A. (1991) Mathematics Children. Use and Understand. Mountain view. CA Mayfield Publishing Company.

12. Ejike (2001) The Effect Of Attitudes Or Performance In Mathematics. Journal of Educational Philosophy, 52 (1), 37-42.

13. Friedman, S. G. (2009). Behavior fundamentals: Filling the behavior-change toolbox. Journal of AppliedCompanion Animal Behavior, 3(1), 36-40.

14. Gnedenko B.A. and Khalil C.K. (1999) A Comparism Of Cue-Controlled Relaxation And Study Skills Counseling In The Treatment Of Mathematics Anxiety. Journal of Educational Psychology. 74,96-103.

15. Hallahan, Kauffman and Lloyd (1996) Effective Instruction: Critical Components of teaching exceptional children.

16. Hudson (2000) The Effect Of Reinforcement And Verbal Rehearsal On Selective Attention In Learning- Disabled Children. National Library of Medicine, Dept of Health Services. New York.

17. Kilpatrick J. (1992) A History of Research in Mathematics (Ed), "Handbook of research on mathematics teaching and learning “(pp3-38) NY: Macmillan.

18. Kynch W.V (1980) Research in Mathematics Education, NCTM, Reston, Virginia.

19. Lovitt J. (1999) A Brief Review of Classroom Group-Oriented Contingencies" Journal of Applied Behaviour Analysis 8.

20. Okebukola, P.A.O (1996). Making Science learnerfriendly:A Challenge for Science Teacher. STANNewsletter, Vol. 3(1).

21. Okorie (2002) A Study Of The Relationship Between Level Of Mathematics Anxiety And Gender Age Mathematical Background And Previous Success In Mathematics. Journal of counseling Psychology 25,441-448.

22. OraiFo (1991) Relationship Of Self Concept Enhancement To Anxiety And Achievement In College Mathematics. (ERIC Document Reproductive Service).

23. Post T.R. (1992) Teaching Mathematics In Grades K-8. Boston: AllynAnd Beacon.

24. Reys R.E. Suydam M.N. and Lindquist M.N. (1995) Helping Children Learn Mathematics. Boston: Allyn and Bacon.

25. Scholfield H.I. (1981) Teacher Effects On Cognitive And Effective Pupil Outcome In Elementary School Mathematics. Journal of Educational Psychology.

26. Simon, M., Tzur, R., Heinz, K., Smith, M. \&Kinzel, M. (1999). On formulating theteacher's role in promoting mathematics learning. In O. Zaslavsky (Ed.), Proceedingsof the 23rd conference of the International Group for the Psychology of MathematicsEducation (Vol. 4, pp. 201-208). Haifa, Israel.Stigler, J.W. \&Hiebert, J. (1999). The teaching gap:

27. Singh E.A. (1991) "The validity of the WISCR Examiner. Verbal Praise Procedure as a concurrent Predicator of the Academic Achievement of Intellectually Superior Students"

28. Suydam M.N. and Higgins J.L. (1977) Activity Based Learning In Elementary School Mathematics: Recommendations from research. "Columbus, $\mathrm{OH}$ Eric clearing house for sciences, mathematics, and environmental Education. 